\title{
Astrocytic Glycogen Influences Axon Function and Survival during Glucose Deprivation in Central White Matter
}

\author{
Regina Wender, ${ }^{1,2}$ Angus M. Brown, ${ }^{1}$ Robert Fern, ${ }^{1}$ Raymond A. Swanson, ${ }^{3}$ Kevin Farrell, ${ }^{3}$ and \\ Bruce R. Ransom ${ }^{1,2}$ \\ Departments of ${ }^{1}$ Neurology and ${ }^{2}$ Physiology and Biophysics, University of Washington School of Medicine, Seattle, \\ Washington 98195, and ${ }^{3}$ Department of Neurology, University of California, San Francisco, and Veterans Affairs Medical \\ Center, San Francisco, California 94121
}

\begin{abstract}
We tested the hypothesis that astrocytic glycogen sustains axon function during and enhances axon survival after $60 \mathrm{~min}$ of glucose deprivation. Axon function in the rat optic nerve (RON), a CNS white matter tract, was monitored by measuring the area of the stimulus-evoked compound action potential (CAP). Switching to glucose-free artificial CSF (aCSF) had no effect on the CAP area for $\sim 30 \mathrm{~min}$, after which the CAP rapidly failed. Exposure to glucose-free aCSF for 60 min caused irreversible injury, which was measured as incomplete recovery of the CAP. Glycogen content of the RON fell to a low stable level $30 \mathrm{~min}$ after glucose withdrawal, compatible with rapid use in the absence of glucose. An increase of glycogen content induced by high-glucose pretreatment increased the latency to CAP failure and improved CAP recovery. Conversely, a decrease of glycogen content induced by norepinephrine pretreatment decreased the
\end{abstract}

latency to CAP failure and reduced CAP recovery. To determine whether lactate represented the fuel derived from glycogen and shuttled to axons, we used the lactate transport blockers quercetin, $\alpha$-cyano-4-hydroxycinnamic acid (4-CIN), and $p$-chloromercuribenzene sulfonic acid ( $p$ CMBS). All transport blockers, when applied during glucose withdrawal, decreased latency to CAP failure and decreased CAP recovery. The inhibitors 4-CIN and $p C M B S$, but not quercetin, blocked lactate uptake by axons. These results indicated that, in the absence of glucose, astrocytic glycogen was broken down to lactate, which was transferred to axons for fuel.

Key words: astrocytes; $\alpha$-cyano-4-hydroxycinnamate; glucose; hypoglycemia; lactate; p-chloromercuribenzene sulfonic acid; quercetin; rat optic nerve
The function of brain glycogen is not well understood. Glycogen turns over rapidly in the brain, however, and turnover is enhanced when adjacent neural activity is increased (Orkand et al., 1973; Pentreath and Kai-Kai, 1982; Swanson et al., 1992). It is appealing to imagine that glycogen might serve to provide fuel to the brain when glucose is in short supply. Indeed, astrocytic glycogen in vitro is degraded rapidly when glucose is withdrawn (Dringen et al., 1993), and glycogen falls rapidly in vivo during ischemia, with a time course that is closely related to the depletion of ATP and the accumulation of lactate (Swanson et al., 1989a). These observations are consistent with the action of glycogen as a fuel source during glucose shortage, but they do not prove this hypothesis. Glycogen content varies by a factor of two or more between brain regions [it is highest in the brainstem and cerebellum and lowest in the striatum and white matter (Swanson et al., 1989a)]. Energy metabolism also varies significantly between different brain regions (Sokoloff et al., 1977). Therefore, glycogen could be more protective against glucose depletion in some areas than in others.

Given all of the above, it is natural to wonder whether glycogen can enhance the survival and function of brain tissue in the absence of glucose. Surprisingly, only a single study, done on cultured cells, has tested this question. Neurons grown in astrocyterich cultures are injured less severely by glucose withdrawal than are neurons in astrocyte-poor cultures (Swanson and Choi, 1993).

Received April 19, 2000; revised June 27, 2000; accepted July 6, 2000.

This research was supported by National Institutes of Health Grants NS15589 (B.R.R.) and NS31914 (R.A.S.), and the Merit Review program of the Department of Veterans' Affairs (R.A.S.). R.W. was supported by National Institutes of Health Clinical Neurosciences Training Program T32 NS07144 (H. R. Winn). We thank Dr. Joel Black (Yale University) for generously providing the electron micrographs. R.W. thanks Dr. Thomas Möller (University of Washington) and Dr. H. Richard Winn (University of Washington, Department of Neurological Surgery) for helpful discussions.

Correspondence should be addressed to Dr. Bruce R. Ransom, Department of Neurology, Box 356465, University of Washington School of Medicine, Seattle, WA 98195. E-mail: bransom@u.washington.edu.

Copyright (C) 2000 Society for Neuroscience $0270-6474 / 00 / 206804-07 \$ 15.00 / 0$
This benefit appears to derive from the presence of greater amounts of glycogen in the astrocyte-rich cultures. Depleting the astrocyte-rich cultures of glycogen negates the benefit (Swanson and Choi, 1993). Two possible mechanisms for this benefit, not mutually exclusive, were suggested but not tested: (1) astrocytes themselves use the energy from glycogen breakdown to prevent the accumulation of toxic levels of glutamate (removing it by a sodium gradient-dependent transporter), or (2) glycogen provides fuel to neurons to sustain their energy metabolism.

We have studied the role of astrocytic glycogen in an in vitro preparation of CNS white matter, the isolated rat optic nerve (RON). An advantage of this preparation is that function can be monitored continuously. Optic nerve function persists for $\sim 30 \mathrm{~min}$ in the absence of glucose (Ransom and Fern, 1997; Fern et al., 1998), suggesting the presence of an intrinsic energy reserve such as astrocytic glycogen. It also is known that the optic nerve, like other neural tissues, can survive on substrates other than glucose, making it feasible that a breakdown product of glycogen other than glucose could mediate the energy transfer between astrocytes and axons (Schurr et al., 1988; Larrabee, 1995; Ransom and Fern, 1997). We tested the hypothesis that axon function and survival depend on astrocytic glycogen when glucose is withdrawn. Our results indicate that glycogen content strongly affected the duration of function and survival of axons after glucose removal and that lactate was probably the molecule that shuttled from astrocytes to axons to mediate energy transfer.

\section{MATERIALS AND METHODS}

Preparation. Long-Evans rats were anesthetized deeply with $\mathrm{CO}_{2}$ and then decapitated. The optic nerves were exposed, gently freed from their dural sheaths, and placed in an interface perfusion chamber (Medical Systems, Greenvale, NY) (see also Stys et al., 1990). Nerves were maintained at $37^{\circ} \mathrm{C}$ and perfused with artificial CSF (aCSF) that contained (in mM): 153 $\mathrm{Na}^{+}, 3 \mathrm{~K}^{+}, 2 \mathrm{Mg}^{2+}, 2 \mathrm{Ca}^{2+}, 143 \mathrm{Cl}^{-}, 26 \mathrm{HCO}_{3}{ }^{-}, 1.25 \mathrm{HPO}_{4}{ }^{2-}$, and 10 glucose. The aCSF was bubbled with a $5 \% \mathrm{CO}_{2}$-containing gas mixture $\left(95 \% \mathrm{~N}_{2} / 5 \% \mathrm{CO}_{2}\right)$ to maintain the $\mathrm{pH}$ at 7.45 . The tissue was oxygenated by a humidified gas mixture $\left(95 \% \mathrm{O}_{2} / 5 \% \mathrm{CO}_{2}\right)$ that flowed over its surface; anoxia was achieved by switching to an $\mathrm{O}_{2}$-free mixture $\left(95 \% \mathrm{~N}_{2} / 5 \% \mathrm{CO}_{2}\right)$. 
Suction electrodes filled with aCSF (of the same composition as the test perfusate for each experiment) were attached to the nerve for stimulation and recording of the compound action potential (CAP) after the nerves were given a $60 \mathrm{~min}$ equilibration period in control aCSF. Stimulus strength was adjusted to evoke the maximum amplitude CAP and then was increased another $25 \%$ to ensure that stimulus strength was always supramaximal.

Data were acquired online (Digidata 1200A, Axon Instruments, Foster City, CA) with proprietary software (Axotape, Axon Instruments). CAP area was calculated with Clampfit (Axon Instruments).

Curve fitting. To standardize data interpretation, we used a mathematical approach to analyze CAP area. This approach is based on the Boltzmann equation because, as illustrated in Figure $1 C$, plotting CAP area against time during glucose removal (our standard insult) resulted in a trace that can be resolved into two sigmoidal curves, each of which can be fit by a Boltzmann function, one with a negative (falling) slope and the other with a positive (rising) slope. Our goal was to use the Boltzmann equation to define precisely the point of CAP decline and the maximum amount of CAP recovery (see Fig. 1C). The Boltzmann relationship is described by:

$$
y=\frac{\max }{1-\exp \left(\frac{V-t}{k}\right)},
$$

where $y$ is the area under the CAP curve, $\max$ is the maximum value of the described sigmoidal (designated $\max _{1}$ for the first sigmoidal, of negative slope, and $\max _{2}$ for the second sigmoidal, of positive slope), $V$ is the time at which the CAP area is $50 \%$ of $\max , t$ is the time, and $k$ is the slope at point $V$. It is important to note that $\max _{1}$ and $\max _{2}$ are not necessarily the highest CAP area values from the baseline and recovery periods, respectively, but rather are the maximum values of the described sigmoidals. The minimum value for any data set is defined by the function as zero. The solid line superimposed on the data set shown in Figure $1 C$ was generated by fitting the Boltzmann equation to the data. The break in the curve, indicated by the downward-pointing vertical arrow, identifies the point at which the equation has identified the zero point. The equation is applied separately to the second curve (of positive slope). In this case the maximum point as determined by curve fitting is represented by $\max _{2}$, which describes CAP recovery. When this equation was applied to every data set, it was possible to calculate the latency of onset of CAP decline, defined as $t=0.95 \cdot \max _{1}$, and CAP recovery, defined as $\left(\max _{2} / \max _{1}\right) \times 100 \%$.

Transmission electron microscopy. Adult male Long-Evans rats were anesthetized deeply with ketamine/xylazine $(40 / 2.5 \mathrm{mg} / \mathrm{kg}$ of body weight, i.p.) and perfused transcardially, first with a PBS solution and then with a fixative solution containing $2 \%$ paraformaldehyde and $2 \%$ glutaraldehyde in $0.14 \mathrm{M}$ phosphate buffer, $\mathrm{pH}$ 7.4. Optic nerves were freed carefully and placed in fresh fixative overnight at $4^{\circ} \mathrm{C}$. Then the tissue was rinsed several times in $0.14 \mathrm{M}$ phosphate buffer, post-fixed in $1 \% \mathrm{OsO}_{4}$ and $1.5 \%$ potassium ferrocyanide in $0.14 \mathrm{M}$ phosphate buffer for $3 \mathrm{hr}$ at $4^{\circ} \mathrm{C}$, and rinsed several times in phosphate buffer. The nerves were dehydrated in a graded ethanol series and embedded in Epon. Silver-gray sections were cut with a Reichardt Ultracut E and contrasted with uranyl acetate and lead citrate.

Glycogen and protein assays. Nerves were placed immediately in $3 \mathrm{ml}$ of ice-cold $85 \%$ ethanol $/ 15 \% 30 \mathrm{~mm} \mathrm{HCl}$. This instantly stops glycogen metabolism. The tissue (in solution) was stored at $-20^{\circ} \mathrm{C}$ until assays were performed. Assays were performed as previously described (Swanson and Choi, 1993). Briefly, the nerves in the ethanol/HCl solution were warmed to room temperature, and the tissue was agitated gently for several hours to permit egress of all glucose (glucose is soluble in this solution, but glycogen is not). Each determination required four optic nerves $(\sim 8 \mathrm{mg}$ of tissue total). The nerves were transferred to $0.3 \mathrm{ml}$ of $30 \mathrm{mM} \mathrm{HCl}$ and sonicated to suspension. Then $50 \mu \mathrm{l}$ of the suspension was removed and added to $200 \mu \mathrm{l}$ of $0.1 \mathrm{~N} \mathrm{NaOH}$ for protein assay by using the Lowry method, in triplicate (Lowry et al., 1951). The remainder was divided into two $100 \mu \mathrm{l}$ fractions. Glycogen was determined by the amyloglucosidase method of Passonneau and Lauderdale (1974). Amyloglucosidase completely hydrolyzes glycogen to glucose. One of the two $100 \mu \mathrm{l}$ fractions (fraction A) was treated with amyloglucosidase, and the other (fraction B) was not. Then the glucose in both fractions was quantified by the glucose6-phosphate dehydrogenase/NADP fluorescence method. Glucose in fraction $B$, which reflects endogenous true glucose in the nerves, was subtracted from glucose in fraction $\mathrm{A}$, which reflects the sum of endogenous glucose and glucose derived from glycogen hydrolysis, to yield glycogen expressed as glucosyl equivalents. In practice, the soaking of the nerves in the ethanol/acid solution removes all detectable glucose such that glucose measured in fraction B was negligible, and all of the glucose measured in fraction A reflects hydrolyzed glycogen. Standards were prepared either from glucose or from rabbit liver glycogen after desiccation at $120^{\circ} \mathrm{C}$. These are found to be equivalent, i.e., the desiccated glycogen digested with amyloglucosidase yields almost exactly the predicted amount of glucose.

Data analysis. Data are presented as means and SEM. Significance was determined by ANOVA with Tukey's post-test, where $p<0.05$ was taken to indicate statistical significance.

\section{RESULTS}

The effects of glucose deprivation on CAP area in adult RONs are shown in Figure 1. CAPs were evoked every $30 \mathrm{sec}$. During a 60
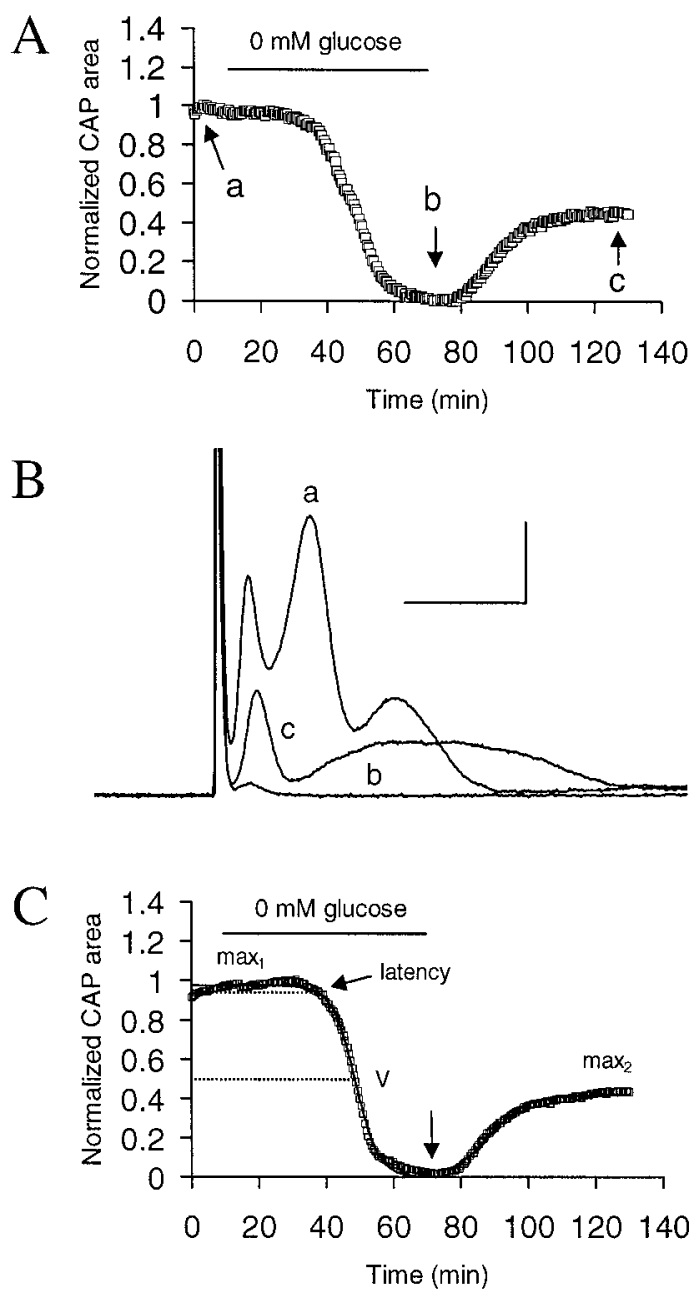

Figure 1. Effects of glucose withdrawal for $60 \mathrm{~min}$ on the rat optic nerve CAP area. $A$, A 60 min period of glucose withdrawal caused failure of the CAP after $\sim 30 \mathrm{~min}$ and resulted in incomplete CAP recovery. Each symbol represents average CAP area (evoked every $30 \mathrm{sec} ; n=15$ ). $B$, Representative CAPs recorded from one of the nerves averaged in $A$. The recordings were taken at the time points indicated $(a-c)$. Calibration: $0.5 \mathrm{mV}, 1 \mathrm{msec}$. $C$, Representative trace from an individual nerve included in $A$ to illustrate the curve-fitting protocol that was used to quantify latency and recovery.

min period of glucose withdrawal the CAP was maintained, on average, for $28.8 \pm 2.1 \mathrm{~min}(n=15)$ before it began to fail (Fig. $1 A)$. It fell rapidly from that point to zero. The CAP recovered to an average of $45.3 \pm 3.7 \%(n=15)$ of the control CAP after a 60 min recovery period in normal aCSF (i.e., containing $10 \mathrm{~mm}$ glucose), indicating that irreversible injury had occurred. This agreed with previously published results (Ransom and Fern, 1997). Figure $1 B$ shows representative CAPs from one of the nerves represented in Figure $1 A$ before the removal of glucose $(a)$, at the conclusion of 60 min of glucose deprivation $(b)$, and after maximum recovery $(c)$. The pattern of CAP recovery shown here was typical; the first peak of the CAP was best preserved. This suggested relative preservation of the larger-diameter axons, but further morphological analysis would be necessary to confirm this. To quantify the effects of glucose withdrawal on the CAP, we adopted a curve-fitting protocol to standardize the analysis of latency to CAP decline and CAP recovery magnitude (Fig. $1 C$; see Materials and Methods for details).

\section{Ultrastructural identification of astrocytic glycogen in the RON}

Electron microscopy studies performed on perfusion-fixed RONs (Fig. 2) showed granules of glycogen located within most astrocytes. No glycogen was seen in axons or oligodendrocytes. No 


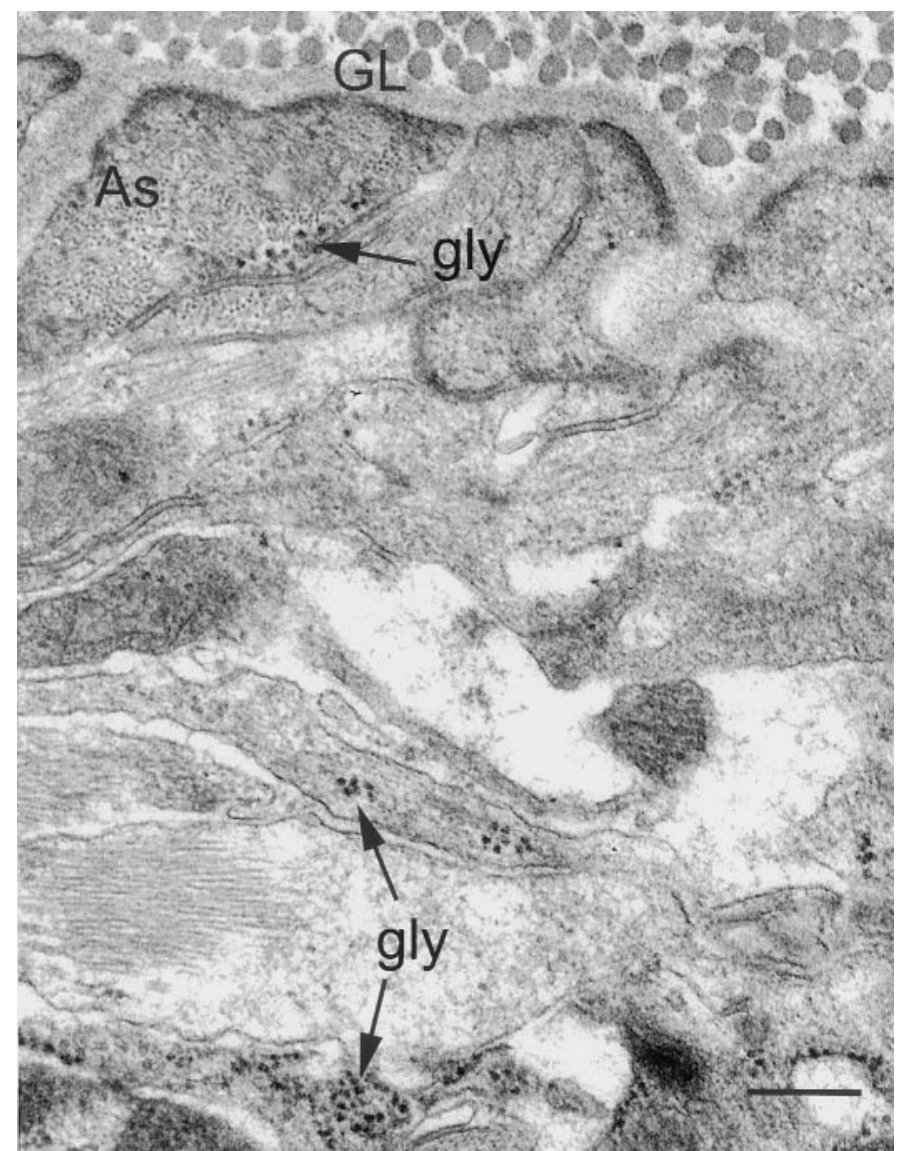

Figure 2. Ultrastructural evidence of glycogen deposition in astrocytes in adult rat optic nerve. Electron micrograph shows accumulations of glycogen granules ( $g l y$ ), which are $\sim 20-25 \mathrm{~nm}$ in diameter, within processes of astrocytes $(A s)$ at the glia limitans $(G L)$. Glycogen granules were not seen in axons nor in oligodendrocytes. Scale bar, $0.25 \mu \mathrm{m}$.

attempts were made to quantify the glycogen seen in this manner. These results agreed with previous studies on other neural areas (Cataldo and Broadwell, 1986; Magistretti et al., 1993).

\section{Glycogen content of RON}

The levels of glycogen in RONs under different conditions were determined by biochemical assay (Fig. 3). Glycogen content declined in vitro after the removal of nerves from the animal. In one set of experiments, for example, glycogen content fell from $10.10 \pm$ $0.72 \mathrm{pmol}$ of glycogen $/ \mu \mathrm{g}$ of protein $(n=6)$ immediately after dissection (i.e., the nerves were never placed in the tissue chamber) to $4.85 \pm 0.31 \mathrm{pmol}$ of glycogen $/ \mu \mathrm{g}$ of protein $(n=6 ; p<0.001)$ in companion nerves that were perfused with control aCSF for 60 min (see Fig. 3B, first bar). Nonetheless, glycogen content of RONs was quite stable after $60 \mathrm{~min}$ of incubation in control aCSF containing $10 \mathrm{~mm}$ glucose (Fig. $3 A$, compare the first and last bars). It should be noted that the absolute values of glycogen in nerves under control conditions (60 min incubation in aCSF containing 10 mu glucose) were variable between assay sets (e.g., Fig. 3, compare the first bar in $A$ with the first bar in $B$ ), but results within each set of assays were internally consistent.

In one set of experiments we investigated the effects of glucose removal on glycogen content. All nerves were given an initial 60 min incubation period in control aCSF containing $10 \mathrm{~mm}$ glucose. The glycogen content fell rapidly with glucose removal (Fig. $3 A$ ). From an initial value of $10.70 \pm 0.45 \mathrm{pmol}$ of glycogen $/ \mu \mathrm{g}$ of protein ( $t=0 \mathrm{~min} ; n=6)$, glycogen fell to $8.37 \pm 0.35 \mathrm{pmol}$ of glycogen $/ \mu$ g of protein after $15 \mathrm{~min}$ of glucose deprivation $(n=6$; $p<0.05$ vs 0 min group) and then to a low stable level after $30 \mathrm{~min}$ $(2.69 \pm 0.30 \mathrm{pmol}$ of glycogen $/ \mu \mathrm{g}$ of protein; $n=6)$. One group of nerves was allowed to recover for $60 \mathrm{~min}$ in control aCSF after the
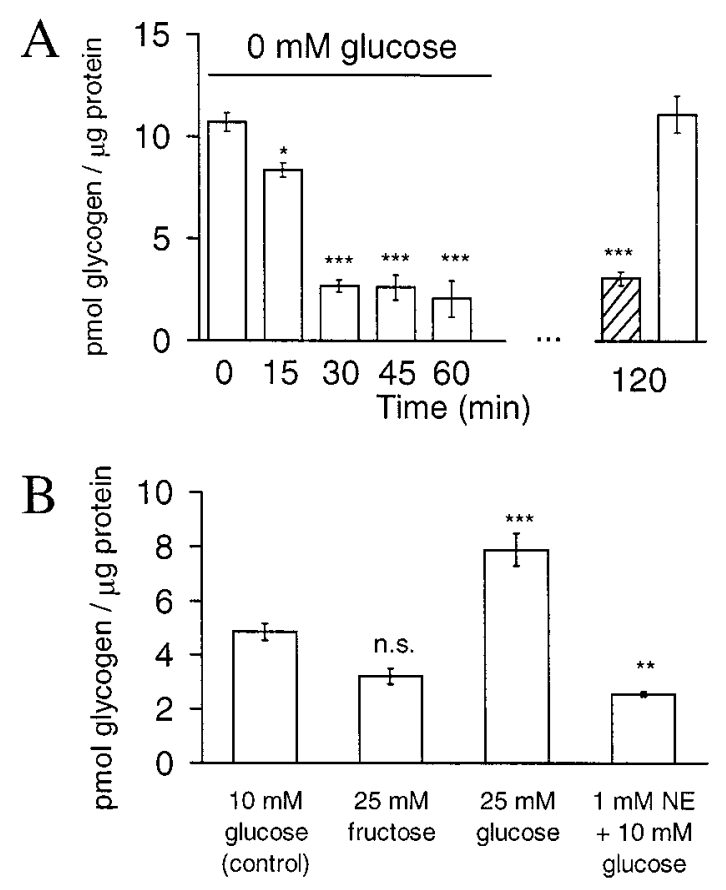

Figure 3. Glycogen content of rat optic nerves after glucose deprivation and pharmacological manipulation. $A$, In the absence of glucose, glycogen content declined over time and reached a low stable level at $30 \mathrm{~min}$. The cross-hatched bar at 120 min shows the glycogen content of nerves that were allowed to recover for $60 \mathrm{~min}$ in control aCSF after the $60 \mathrm{~min}$ period of glucose withdrawal. The clear bar at 120 min represents the glycogen content of nerves that were perfused with control aCSF for the entire 120 min test period, with no exposure to glucose-free aCSF. Time (min) refers to the time elapsed from the beginning of glucose-free perfusion. All of the nerves in this experiment were incubated first in control aCSF for $60 \mathrm{~min}$; $n=6$ for all conditions except $60 \mathrm{~min}(n=4)$. Error bars indicate SEM. $* p<0.05$ and $* * * p<0.001$ as compared with 0 min. $B$. Incubation of nerves with $25 \mathrm{~mm}$ glucose increased glycogen content, and incubation with NE caused glycogen to decline. Glycogen content in nerves pretreated with 25 $\mathrm{mm}$ fructose was not significantly different from control. All of the nerves were incubated for $60 \mathrm{~min}$ in the indicated substrate beginning immediately after their removal from the animal; $n=6$ for each group except NE ( $n=$ 7). Error bars indicate SEM. n.s., Not significant; ${ }^{* *} p<0.01$ and ${ }^{* * *} p<$ 0.001 as compared with control.

$60 \mathrm{~min}$ period of glucose withdrawal (cross-hatched bar at $120 \mathrm{~min}$ in Fig. $3 A ; 3.06 \pm 0.33 \mathrm{pmol}$ of glycogen $/ \mu \mathrm{g}$ of protein; $n=6$ ). Glycogen content in this group was not significantly different from glycogen content in nerves that were not given a recovery period ( $p>0.05$ compared with nerves collected at 30,45, and $60 \mathrm{~min}$ ). The glycogen content of nerves that were simply perfused with control aCSF for the entire 120 min test period, with no period of glucose deprivation, was not significantly different from the control nerve glycogen content $(11.1 \pm 0.89 \mathrm{pmol}$ of glycogen $/ \mu \mathrm{g}$ of protein; $n=6 ; p>0.05$ compared with control and $p<0.001$ compared with cross-hatched bar).

As a crucial step to testing the effects of glycogen on RON function, we determined whether RON glycogen content could be modulated. These results are shown in Figure $3 B$. For this set of nerves the control population incubated for $60 \mathrm{~min}$ in normal aCSF contained $4.85 \pm 0.31 \mathrm{pmol}$ of glycogen $/ \mu \mathrm{g}$ of protein $(n=6)$. In other preparations exposure to high glucose concentration increases glycogen content (Prasannan and Subrahmanyam, 1966; Swanson et al., 1989b; Dringen and Hamprecht, 1992), whereas exposure to norepinephrine causes glycogen content to fall (Quach et al., 1978; Magistretti, 1988; Magistretti et al., 1993). Incubation of nerves in $25 \mathrm{~mm}$ glucose for $60 \mathrm{~min}$ induced an increase in glycogen stores to $7.90 \pm 0.59 \mathrm{pmol}$ of glycogen $/ \mu \mathrm{g}$ of protein $(n=$ $6 ; p<0.001$ vs control); conversely, pretreatment for $60 \mathrm{~min}$ with $1 \mathrm{~mm}$ norepinephrine led to a decline in RON glycogen $(2.56 \pm$ $0.08 \mathrm{pmol}$ of glycogen $/ \mu \mathrm{g}$ of protein; $n=7 ; p<0.01$ vs control). Fructose can sustain the CAP in the absence of glucose (R. Wender, 

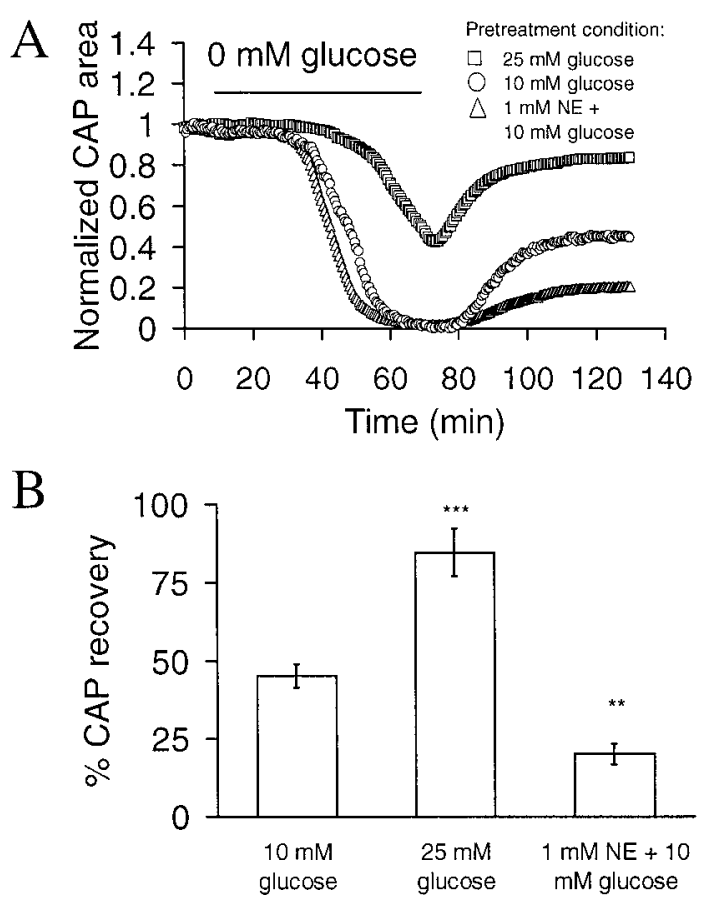

Figure 4. Effect of nerve glycogen content on axon function during, and recovery from, a $60 \mathrm{~min}$ period of glucose deprivation. $A$, Increase of glycogen by pretreatment of optic nerves with $25 \mathrm{~mm}$ glucose $(n=6)$ delayed the onset of CAP area decline during 60 min of glucose deprivation as compared with control $(n=15)$. Under these conditions the magnitude of CAP recovery was greater. Decrease of glycogen by pretreatment with $1 \mathrm{mM}$ norepinephrine decreased the extent of CAP recovery $(n=9)$. $B$, Percentage of CAP recovery $60 \mathrm{~min}$ after exposure to glucose-free aCSF for the nerves represented in $A$. Control nerves showed recovery of CAP area to $45.3 \pm 3.7 \%$. Pretreatment of nerves with $25 \mathrm{~mm}$ glucose increased CAP recovery, and incubation with $1 \mathrm{~mm}$ norepinephrine had the opposite effect. ${ }^{*} p<0.01$ and ${ }^{* * *} p<0.001$ as compared with $10 \mathrm{~mm}$ glucose group.

A. Brown, and B. Ransom, unpublished observations) but does not lead to glycogen formation in vitro (Wiesinger et al., 1997). As expected, nerves equilibrated for $60 \mathrm{~min}$ in $25 \mathrm{~mm}$ fructose had no change in glycogen content as compared with control $(3.23 \pm 0.29$ pmol of glycogen $/ \mu \mathrm{g}$ of protein; $n=6 ; p>0.05 \mathrm{vs}$ control); the significance of this observation is discussed later.

\section{Glycogen content and axon function}

To determine whether RON glycogen content affected axon function during glucose withdrawal, we assessed the CAP during glucose withdrawal in nerves for which the glycogen was increased or decreased (Fig. 4). Nerves with increased glycogen (i.e., preincubated with $25 \mathrm{~mm}$ glucose), as compared with control nerves, showed increased latency to CAP area decline during glucose deprivation $[41.5 \pm 4.9 \mathrm{~min}(n=6)$ vs control at $28.9 \pm 2.1 \mathrm{~min}$ $(n=15) ; p<0.05]$. The CAP never fell to zero during aglycemia in the high-glycogen nerves (Fig. 4A). Nerves with decreased glycogen (i.e., preincubated with $1 \mathrm{~mm}$ norepinephrine) all had latencies to CAP decline of $<28 \mathrm{~min}$, the average latency to CAP decline in control nerves, but this trend did not reach statistical significance $(23.2 \pm 1.1 \mathrm{~min} ; n=9 ; p>0.05$ vs control). The magnitude of post-aglycemia CAP recovery for nerves with variable glycogen content is illustrated in Figure $4 B$. CAP recovery after glucose withdrawal was significantly greater in high-glycogen nerves $(85.8 \pm 7.2 \% ; n=6 ; p<0.001)$ and significantly less in low-glycogen nerves $(20.2 \pm 3.3 \% ; n=9 ; p<0.01)$ as compared with control tissue $(45.3 \pm 3.7 \% ; n=15)$.

To confirm that the results observed with $25 \mathrm{~mm}$ glucose were attributable to the presence of increased glycogen stores and were not merely a consequence of "loading" of the extracellular space with elevated glucose, we performed a series of experiments with $25 \mathrm{~mm}$ fructose. Fructose, like glucose, sustains the CAP, but it
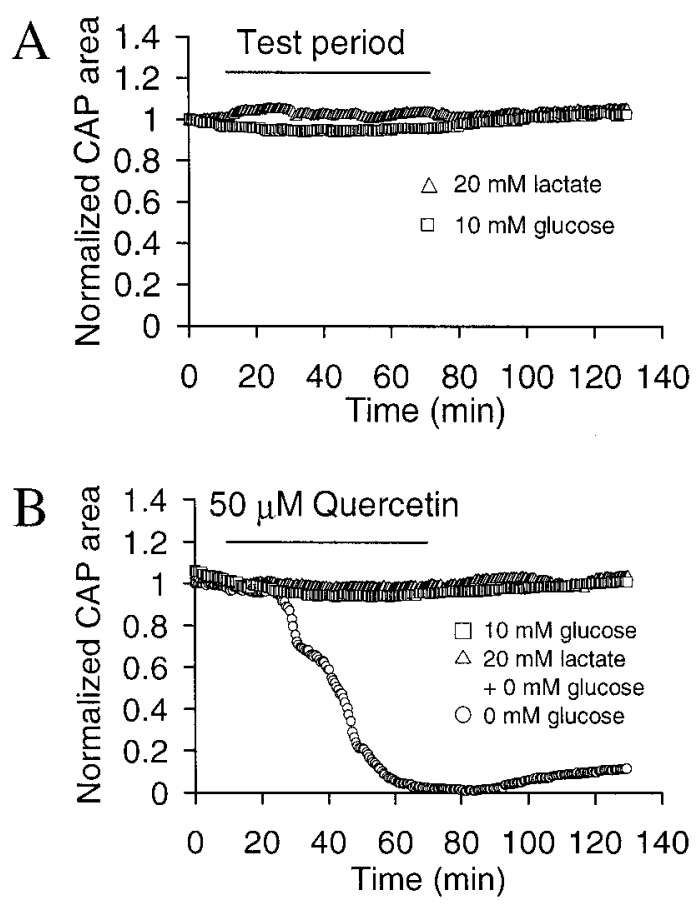

Figure 5. Lactate supported RON function in the absence of glucose and in the presence of the lactate transport blocker quercetin. $A$, Nerves continually perfused with control aCSF showed no decline in average CAP area over $120 \mathrm{~min}(n=6)$. Lactate could substitute for glucose in maintaining the CAP for the $60 \mathrm{~min}$ period shown by the solid horizontal line $(n=6)$. B, Effect of quercetin $(50 \mu \mathrm{M})$ on RONs subjected to $60 \mathrm{~min}$ of glucose withdrawal. Quercetin had no effect on the average CAP of nerves perfused with $10 \mathrm{~mm}$ glucose $(n=6)$. Quercetin also had no effect on the CAP of nerves exposed to $20 \mathrm{~mm}$ lactate during glucose withdrawal $(n=6)$. When quercetin was applied during $0 \mathrm{~mm}$ glucose exposure, however, there was a decline in CAP area and reduced recovery $(n=7)$.

does not induce glycogen synthesis (Wiesinger et al., 1997) (see Fig. $3 B$ ). There was no statistically significant difference in either latency to CAP decline or CAP recovery between nerves pretreated with $25 \mathrm{~mm}$ fructose versus control nerves pretreated with $10 \mathrm{~mm}$ glucose (latency, $27.6 \pm 2.2 \mathrm{~min}$; recovery, $59.0 \pm 7.4 \% ; n=$ $6 ; p>0.05)$. This result with fructose suggested that the effects of $25 \mathrm{~mm}$ glucose were attributable to glycogen and not to lingering amounts of substrate in the extracellular space.

We determined whether glycogen content would affect the latency of CAP failure or the degree of CAP recovery after an anoxic insult as opposed to an aglycemic insult. Nerves with increased or decreased glycogen content were subjected to 60 min periods of anoxia. RON glycogen content had no apparent effect on the time course of CAP failure or on the degree of CAP recovery from anoxia (data not shown).

\section{Blockade of lactate transport and axon function during glucose withdrawal}

Nerves in control aCSF containing $10 \mathrm{~mm}$ glucose maintained robust CAPs for several hours (Fig. $5 A$ ), in agreement with Stys et al. (1991). A metabolically equivalent concentration of lactate (i.e., $20 \mathrm{~mm}$ ) could be substituted for glucose for a 60 min test period with no loss of CAP area $(106 \pm 8.9 \%$ of baseline CAP area; $n=$ 6 ; at $t=130 \mathrm{~min}$; Fig. $5 A$ ). These data strongly supported the hypothesis that lactate can support axon function as effectively as can glucose, at least for the period that was tested.

Because lactate served as an effective energy source for axon function and appears in the extracellular space with glycogen breakdown (Dringen et al., 1993; Wiesinger et al., 1997), we attempted to interfere with lactate transport to test the theory that lactate was transferred from astrocytes to axons during glucose deprivation. We first tested the bioflavonoid quercetin, which preferentially blocks extrusion of lactate (Belt et al., 1979; Volk et al., 

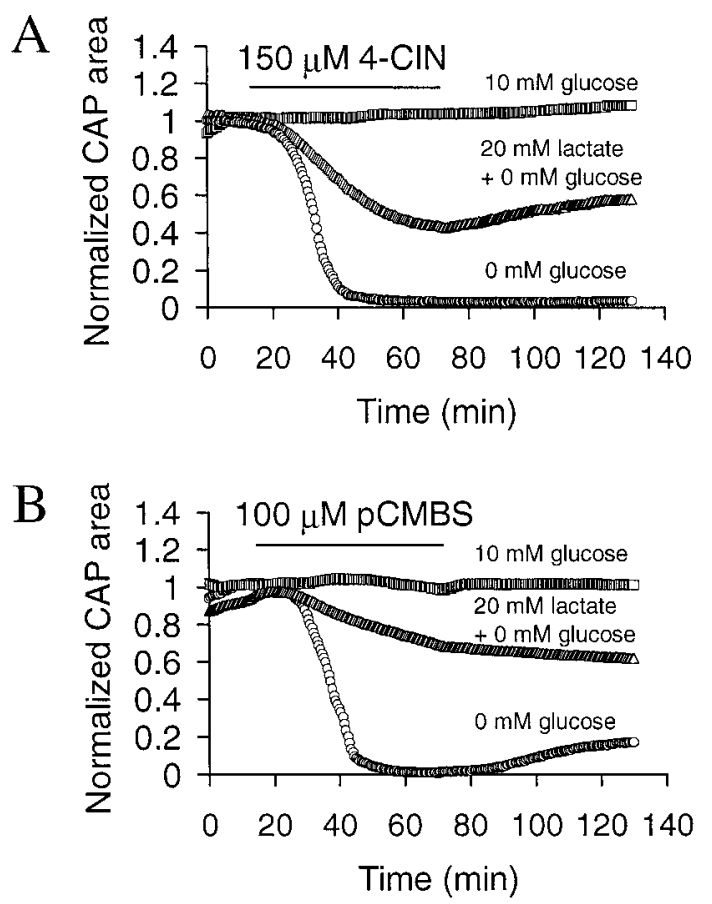

Figure 6. Effect of the lactate transport inhibitors 4-CIN and $p$ CMBS on RONs exposed to 0 or $10 \mathrm{~mm}$ glucose or $20 \mathrm{~mm}$ lactate for $60 \mathrm{~min}$. $A, \alpha$-Cyano-4-hydroxycinnamic acid $(4-C I N ; 150 \mu \mathrm{M})$ had no effect on the average CAP in the presence of glucose. 4-CIN led to a loss of function in nerves substituted with $20 \mathrm{~mm}$ lactate. 4-CIN caused rapid CAP failure in nerves exposed to $0 \mathrm{~mm}$ glucose and a lower recovery of baseline CAP area. $B, p$-Chloromercuribenzene sulfonic acid $(p C M B S ; 100 \mu \mathrm{M})$ had no effect on the CAP in the presence of glucose. $p$ CMBS led to a loss of function in nerves perfused with aCSF in which glucose had been substituted with $20 \mathrm{~mm}$ lactate. When $p$ CMBS was applied to nerves exposed to unsupplemented $0 \mathrm{~mm}$ glucose, CAP recovery declined as compared with control conditions. All traces in $A$ and $B$ represent an average of six experiments.

1997). Nerves were perfused with $50 \mu \mathrm{M}$ quercetin for $20 \mathrm{~min}$ before and during the $60 \mathrm{~min}$ period of glucose withdrawal. In the presence of quercetin the latency to CAP failure was $23.3 \pm 2.8$ $\min (n=7)$ as compared with $28.9 \pm 2.1 \mathrm{~min}$ in control experiments $(p>0.05$; Fig. $5 B)$. These nerves sustained a greater degree of irreversible injury than did control nerves $(12.3 \pm 3.4 \%$ vs $45.3 \pm$ $3.7 \%$ control; $p<0.001)$. It appeared that quercetin blocked lactate efflux in the RON, because quercetin did not prevent lactate, exogenously applied, from supporting the CAP in the absence of glucose $(\mathrm{CAP}$ area $=105 \pm 7.1 \%$ at $t=130 \mathrm{~min} ; n=6$; Fig. $5 B)$. As a control, quercetin was applied during continuous perfusion with glucose-containing aCSF. It was without effect under these conditions (Fig. $5 B$ ).

Two other lactate transport inhibitors, $\alpha$-cyano-4-hydroxycinnamic acid (4-CIN) and $p$-chloromercuribenzene sulfonic acid ( $p \mathrm{CMBS})$, were tested for their effects on axon function during glucose deprivation (Fig. 6). Both compounds had no effect on the CAP in the continuous presence of glucose. 4-CIN $(150 \mu \mathrm{M})$, applied $20 \mathrm{~min}$ before, and during, $60 \mathrm{~min}$ of glucose deprivation, decreased latency to CAP decline to $17.5 \pm 3.2 \mathrm{~min}(n=6 ; p<$ 0.05 vs control; Fig. $6 A)$. 4-CIN-treated nerves recovered only minimally $(3.5 \pm 1.0 \% ; n=6 ; p<0.001$ vs control). It appeared that 4-CIN blocked lactate uptake by RON axons because, in the presence of 4-CIN, $20 \mathrm{~mm}$ lactate in glucose-free aCSF was not able to support the CAP fully (Fig. $6 A$ ). In the presence of 4-CIN and lactate, CAP area declined and showed irreversible injury $(58.2 \pm 5.4 \% ; n=6 ; p<0.001$ compared with nerves perfused with lactate alone).

When $p$ CMBS, a specific blocker of the monocarboxylate transporter isoform MCT1 (Halestrap and Price, 1999; Juel and Halestrap, 1999), was applied during glucose withdrawal, latency to CAP decline was $19.5 \pm 2.6 \min (n=6 ; p>0.05$ vs 0 mm glucose

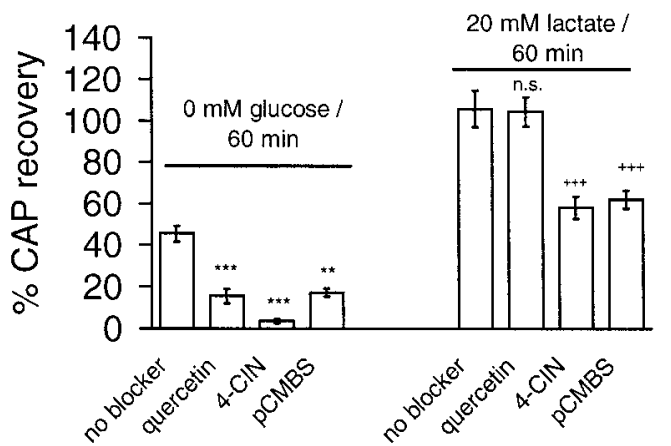

Figure 7. Summary of CAP recoveries after aglycemia with inhibition of lactate transport, with and without lactate supplementation. The four bars on the left represent nerves that were subjected to a $60 \mathrm{~min}$ period of glucose withdrawal, i.e., no exogenous substrate was provided. A second set of nerves, represented by the four bars on the right, was exposed to the indicated lactate transport blockers during aglycemia but in the presence of $20 \mathrm{~mm}$ lactate. Each bar represents a minimum of six experiments. Error bars indicate SEM. ${ }^{* *} p<0.01$ and $* * * p<0.001$ as compared with no blocker in $0 \mathrm{~mm}$ glucose group; ${ }^{+++} p<0.001$. n.s., Not significant as compared with no blocker in $20 \mathrm{~mm}$ lactate group.

control), and CAP recovery was reduced to $17.1 \pm 1.9 \%$ of baseline CAP area $(n=6 ; p<0.01$ compared with recovery under control conditions; Fig. $6 B$ ). When applied in the presence of $20 \mathrm{~mm}$ lactate for the test period, $p C M B S$ caused a fall in CAP area beginning at $29.5 \pm 2.9 \mathrm{~min}$ and an inevitable loss of CAP area $(62.0 \pm 4.4 \%$ of baseline CAP area; $n=6 ; p<0.001)$. These results suggested that MCT1 must be present on axons in adult RON. The effects of the lactate transport blockers on the percentage of CAP recovery from $60 \mathrm{~min}$ of aglycemia or on exposure to $20 \mathrm{~mm}$ lactate are summarized in Figure 7.

\section{DISCUSSION}

Our results support the hypothesis that, during glucose deprivation in white matter, astrocytes supply energy substrate to axons in the form of lactate derived from glycogen. This is, to our knowledge, the first demonstration of the importance of astrocytic glycogen for axon function and survival during glucose withdrawal. Our conclusions are based on the following observations: (1) the RON contained glycogen localized exclusively in astrocytes; (2) in the absence of glucose, RON axons remained functional for $30 \mathrm{~min}$ and then failed with a time course that mirrored glycogen loss; (3) RON function during and after $60 \mathrm{~min}$ of glucose removal was enhanced by increasing glycogen content and decreased by decreasing glycogen content; (4) lactate supported RON function in the absence of glucose; and (5) blockade of transmembrane lactate transport decreased RON function in the absence of glucose.

The persistence of the CAP for $30 \mathrm{~min}$ without glucose suggested the presence of an intrinsic energy reserve. Brain glycogen, localized almost exclusively in astrocytes (see Fig. 2), is a prime candidate to fill this role (Cataldo and Broadwell, 1986; Magistretti et al., 1993). The preservation of the CAP in glucose-free aCSF was not attributable to persistent glucose within the tissue. Glucose concentration in the extracellular space $\left([\text { glucose }]_{\mathrm{o}}\right)$ would be less than in the bulk perfusate because diffusion of glucose is likely to be slow compared with glucose use. Even in vivo, in which the diffusion distances would be much less than in the isolated RON, the $[\text { glucose }]_{0}$ is only approximately one-third of that in blood (Silver and Erecinska, 1994). Direct measurements of [glucose] in cortex indicate that it falls within minutes to unmeasurable levels when the exogenous supply is interrupted (Siesjö, 1978; Silver and Erecinska, 1994), consistent with the high rate of glucose consumption by brain tissue at $37^{\circ} \mathrm{C}$ (Siesjö, 1978).

We feel confident that the electron-dense particles located in glial end-feet (see Fig. 2) are glycogen, on the basis of two observations. First, the only other structure with which these might be confused is free ribosomes, which at $10-15 \mathrm{~nm}$ are too small to have accounted for the structures in Figure 2 (which are 20-40 


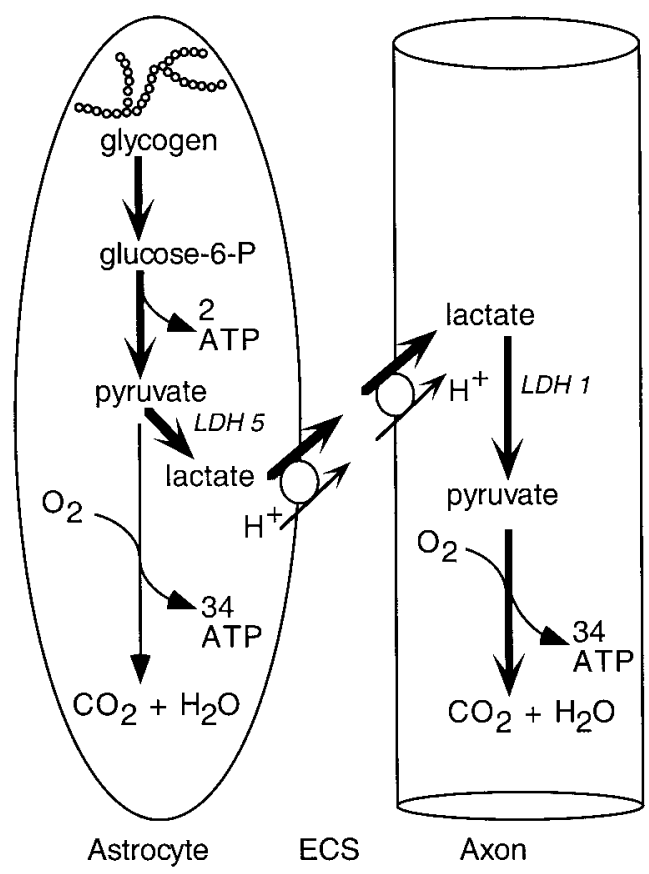

Figure 8. Schematic illustration of how astrocytic glycogen appears to fuel axons in the absence of glucose. In the absence of glucose the astrocytic glycogen is broken down to lactate, which is transported to the extracellular space $(E C S)$ via a MCT. Then it is taken up by a MCT in axons and is metabolized oxidatively to produce the energy needed to sustain excitability. $L D H 5$ preferentially reduces pyruvate to lactate, and $L D H 1$ preferentially oxidizes lactate to pyruvate. This scheme recognizes that astrocytes can subsist, at least transiently, on glycolytic energy metabolism, whereas axons require oxidative metabolism.

$\mathrm{nm})$. Second, the pattern of glycogen distribution illustrated in Figure 2 is consistent with what has been shown in previous ultrastructural studies (Peters and Palay, 1976; Cataldo and Broadwell, 1986; Clarke and Sokoloff, 1999). This ultrastructural picture is consistent with in vitro experiments indicating that only astrocytes generate measurable quantities of glycogen (Dringen et al., 1993; Wiesinger et al., 1997).

In the absence of glucose the glycogen content fell to a low, stable level by 30 min (see Fig. $3 A$ ), closely corresponding to the time at which axonal conduction failed. Glucose controls glycogen content by binding and inactivating the glycogen breakdown enzyme phosphorylase A (Stryer, 1995). It is not surprising that nerve glycogen content remained at a low plateau level after 30 min of glucose withdrawal rather than falling to zero. Cultured astrocytes are not able to mobilize their glycogen stores completely in the absence of glucose (Lomako et al., 1993, 1995). Glycogen is composed of a protein core, glycogenin, with many attached glucose residues. Astrocytes do not degrade glycogen all the way to the free glycogenin (Wiesinger et al., 1997).

Changes in RON glycogen content had significant functional consequences. Nerves with amplified glycogen stores maintained normal conduction for 12 min longer than did control nerves during glucose deprivation, and they showed much higher levels of CAP recovery after the insult. Moreover, CAP area never fell to zero in the high glycogen-containing nerves during aglycemia. In NEtreated nerves, with diminished glycogen, CAP recovery was less than in control nerves.

Our results supported the model shown in Figure 8. The model asserts that astrocytes contain glycogen, which is converted into lactate for transport to axons during glucose deprivation. Lactate is the most likely fuel to be transferred from astrocytes to axons for the following reasons: (1) astrocytes, but not neurons, are known to extrude large amounts of lactate (Walz and Mukerji, 1990); (2) astrocytes, but not neurons, can survive for a limited time on anaerobic metabolism alone (Goldberg and Choi, 1993; Pappas and
Ransom, 1995; Ransom and Fern, 1996) and could "afford" to export large amounts of lactate; (3) lactate, but not glucose, is released from astrocytes when glucose is removed (Dringen et al., 1993); (4) lactate has been shown to be an effective fuel in numerous types of CNS tissue (Larrabee, 1983; Schurr et al., 1988; Izumi et al., 1994; Izumi et al., 1997), including RON axons (Wender et al., 1999); (5) lactate from Müller cells fuels photoreceptors in guinea pig retina (Poitry-Yamate et al., 1995). According to the model, axons import lactate for subsequent oxidative metabolism to generate ATP. This model reflects the constraint that lactate could be metabolized by axons only in the presence of oxygen, and our results confirm this. Clinically, our model would operate during hypoglycemia. Astrocytes also may supply axons with lactate from glycogen breakdown during high energy demand, when extracellular glucose levels would be expected to fall.

For astrocytes to convert glycogen to lactate for transfer to axons as a fuel in the absence of glucose (i.e., Fig. 8), several conditions must be met. There must be appropriate enzymes for the creation of lactate in astrocytes and for its use in axons, and there also must be appropriate transport mechanisms for lactate movement. Indeed, the expression patterns in the CNS of lactate dehydrogenase (LDH) and the monocarboxylate transporter (MCT) seem well suited to accommodate these needs. LDH, the enzyme catalyzing interconversion of pyruvate and lactate (Stryer, 1995), is composed of various combinations of two subunits, $\mathrm{H}$ (or LDH1) and M (or LDH5). Tetramers composed primarily of the former subunit preferentially oxidize lactate to pyruvate, and tetramers composed principally of the latter subunit predominantly reduce pyruvate to lactate (Stryer, 1995). Neurons, highly dependent on oxidative metabolism (Siesjö, 1978), stain exclusively with anti-H (antiLDH1) antibodies (Bittar et al., 1996). Astrocytes, which have less active oxidative enzymes (Friede, 1962), are stained by both M (LDH5) and $\mathrm{H}$ antibodies. Thus astrocytes, expressing at least some LDH5, can convert pyruvate to lactate readily, and neurons, expressing LDH1, are specialized to oxidize lactate to pyruvate.

MCTs, of which there are several isoforms, shuttle lactate and pyruvate across cell membranes by using proton symport (Poole and Halestrap, 1993). There are several isoforms of MCTs. MCT1 appears to be expressed in tissue that preferentially releases lactate, and MCT2 is expressed in tissues that mainly consume lactate (Jackson and Halestrap, 1996; Broer et al., 1997). MCT1 is the only MCT expressed by astrocytes, whereas neurons express MCT2 (Broer et al., 1997; Koehler-Stec et al., 1998). MCT2 has a 10-fold higher affinity for substrates than does MCT1 and is, therefore, ideally suited for uptake at low substrate concentrations (Halestrap and Price, 1999). Additionally, because $\mathrm{pH}$ gradients drive transmembrane lactate movement (Poole and Halestrap, 1993; Juel, 1997), glycolytically generated lactic acid could initiate its own export. The expression patterns of $\mathrm{LDH}$ and MCT isoforms would tend to make astrocytes a lactate source and make axons a lactate sink.

The model is supported by the results of inhibiting lactate transport, which would be predicted to block the movement of lactate between astrocytes and axons. All three MCT blockers that were tested reduced CAP recovery after a $60 \mathrm{~min}$ period of glucose withdrawal. Quercetin preferentially inhibits lactate efflux from cells (Belt et al., 1979) (see also McKenna et al., 1998). When 20 $\mathrm{mm}$ lactate was added to the glucose-free perfusate, quercetin had no effect on the CAP (see Fig. $5 B$ ), consistent with the idea that the drug did not affect lactate influx into axons. 4-CIN preferentially blocks MCT2 (Halestrap and Price, 1999). In contrast to quercetin, 4-CIN partially blocked the ability of exogenous lactate to support axonal function during glucose removal (see Fig. 6A). Because 4-CIN is a competitive inhibitor, it is not surprising that axon function was maintained to some degree during perfusion with 20 mu lactate plus 4-CIN (Edlund and Halestrap, 1988).

The inhibitor 4-CIN can have effects on mitochondrial pyruvate transport (Juel and Halestrap, 1999) that can lead to a misinterpretation of results. For this reason we used a third lactate transport blocker. $p$ CMBS, which is highly specific for MCT1 (Broer et al., 1998; Broer et al., 1999; Halestrap and Price, 1999; Juel and 
Halestrap, 1999), gave similar results to those observed with 4-CIN (see Figs. $6 B, 7$ ). Considering that $p$ CMBS partially blocked the ability of exogenous lactate to sustain the CAP, our data suggest that axon membranes express some MCT1.

Our results support the idea that astrocytic glycogen acted as a readily available source of energy (i.e., lactate) for axons when glucose was withdrawn. This glial-neuronal interaction, although long a theoretical possibility and suggested by earlier tissue culture experiments (Swanson and Choi, 1993), had not been demonstrated previously. It was surprising that glycogen was able to sustain nerve function for up to $30 \mathrm{~min}$. It has been assumed that glycogen content in the brain could sustain neural function for $<5$ min (Clarke and Sokoloff, 1999). It may be that white matter, with a lower metabolic rate than gray matter, is unique in this regard.

\section{REFERENCES}

Belt JA, Thomas JA, Buchsbaum RN, Racker E (1979) Inhibition of lactate transport and glycolysis in Ehrlich ascites tumor cells by bioflavonoids. Biochemistry 18:3506-3511.

Bittar PG, Charnay Y, Pellerin L, Bouras C, Magistretti PJ (1996) Selective distribution of lactate dehydrogenase isoenzymes in neurons and astrocytes of human brain. J Cereb Blood Flow Metab 16:1079-1089.

Broer S, Rahman B, Pellegri G, Pellerin L, Martin JL, Verleysdonk S, Hamprecht B, Magistretti PJ (1997) Comparison of lactate transport in astroglial cells and monocarboxylate transporter 1 (MCT 1) expressing Xenopus laevis oocytes. Expression of two different monocarboxylate transporters in astroglial cells and neurons. J Biol Chem 272:30096-30102.

Broer S, Schneider HP, Broer A, Rahman B, Hamprecht B, Deitmer JW (1998) Characterization of the monocarboxylate transporter 1 expressed in Xenopus laevis oocytes by changes in cytosolic $\mathrm{pH}$. Biochem $\mathrm{J}$ 333:167-174.

Broer S, Broer A, Schneider HP, Stegen C, Halestrap AP, Deitmer JW (1999) Characterization of the high-affinity monocarboxylate transporter MCT2 in Xenopus laevis oocytes. Biochem J 341:529-535.

Cataldo AM, Broadwell RD (1986) Cytochemical identification of cerebral glycogen and glucose-6-phosphatase activity under normal and experimental conditions. I. Neurons and glia. J Electron Microsc Tech 3:413-437.

Clarke DD, Sokoloff L (1999) Circulation and energy metabolism of the brain. In: Basic neurochemistry: molecular, cellular, and medical aspects, 6th Ed (Siegel GJ, Agranoff BW, Albers RW, Fisher SK, Uhler MD, eds), pp 637-669. Philadelphia: Lippincott-Raven.

Dringen R, Hamprecht B (1992) Glucose, insulin, and insulin-like growth factor I regulate the glycogen content of astroglia-rich primary cultures. J Neurochem 58:511-517.

Dringen R, Gebhardt R, Hamprecht B (1993) Glycogen in astrocytes: possible function as lactate supply for neighboring cells. Brain Res 623:208-214.

Edlund GL, Halestrap AP (1988) The kinetics of transport of lactate and pyruvate into rat hepatocytes. Evidence for the presence of a specific carrier similar to that in erythrocytes. Biochem J 249:117-126.

Fern R, Davis P, Waxman SG, Ransom BR (1998) Axon conduction and survival in CNS white matter during energy deprivation: a developmental study. J Neurophysiol 79:95-105.

Friede RL (1962) Cytochemistry of normal and reactive astrocytes. J Neuropathol Exp Neurol 21:471-478.

Goldberg MP, Choi DW (1993) Combined oxygen and glucose deprivation in cortical cell culture: calcium-dependent and calcium-independent mechanisms of neuronal injury. J Neurosci 13:3510-3524.

Halestrap AP, Price NT (1999) The proton-linked monocarboxylate transporter (MCT) family: structure, function, and regulation. Biochem J 343:281-299.

Izumi Y, Benz AM, Zorumski CF, Olney JW (1994) Effects of lactate and pyruvate on glucose deprivation in rat hippocampal slices. NeuroReport 5:617-620.

Izumi Y, Benz AM, Katsuki H, Zorumski CF (1997) Endogenous monocarboxylates sustain hippocampal synaptic function and morphological integrity during energy deprivation. J Neurosci 17:9448-9457.

Jackson VN, Halestrap AP (1996) The kinetics, substrate, and inhibitor specificity of the monocarboxylate (lactate) transporter of rat liver cells determined using the fluorescent intracellular $\mathrm{pH}$ indicator, $2^{\prime}, 7^{\prime}$ bis(carboxyethyl)-5(6)-carboxyfluorescein. J Biol Chem 271:861-868.'

Juel C (1997) Lactate-proton cotransport in skeletal muscle. Physiol Rev 77:321-358.

Juel C, Halestrap AP (1999) Lactate transport in skeletal muscle-role and regulation of the monocarboxylate transporter. J Physiol (Lond) 517:633-642.

Koehler-Stec EM, Simpson IA, Vannucci SJ, Landschulz KT, Landschulz WH (1998) Monocarboxylate transporter expression in mouse brain. Am J Physiol 275:E516-E524.

Larrabee MG (1983) Lactate uptake and release in the presence of glucose by sympathetic ganglia of chicken embryos and by neuronal and non-neuronal cultures prepared from these ganglia. J Neurochem 40:1237-1250.
Larrabee MG (1995) Lactate metabolism and its effects on glucose metabolism in an excised neural tissue. J Neurochem 64:1734-1741.

Lomako J, Lomako WM, Whelan WJ, Dombro RS, Neary JT, Norenberg MD (1993) Glycogen synthesis in the astrocyte: from glycogenin to proglycogen to glycogen. FASEB J 7:1386-1393.

Lomako J, Lomako WM, Whelan WJ (1995) Glycogen metabolism in quail embryo muscle. The role of the glycogenin primer and the intermediate proglycogen. Eur J Biochem 234:343-349.

Lowry OH, Rosebrough NJ, Farr AL, Randall AR (1951) Protein measurement with the Folin phenol reagent. J Biol Chem 193:265-275.

Magistretti PJ (1988) Regulation of glycogenolysis by neurotransmitters in the central nervous system. Diabete Metab 14:237-246.

Magistretti PJ, Sorg O, Martin J-L (1993) Regulation of glycogen metabolism in astrocytes: physiological, pharmacological, and pathological aspects. In: Astrocytes: pharmacology and function (Murphy S, ed), pp 243-265. San Diego, CA: Academic.

McKenna MC, Tildon JT, Stevenson JH, Hopkins IB, Huang X, Couto R (1998) Lactate transport by cortical synaptosomes from adult rat brain: characterization of kinetics and inhibitor specificity. Dev Neurosci 20:300-309.

Orkand PM, Bracho H, Orkand RK (1973) Glial metabolism: alteration by potassium levels comparable to those during neural activity. Brain Res 55:467-471.

Pappas CA, Ransom BR (1995) The effects of anoxia and simulated ischemia on the viability of cultured rat hippocampal astrocytes. Soc Neurosci Abstr 21:211.

Passonneau JV, Lauderdale VR (1974) A comparison of three methods of glycogen measurement in tissues. Anal Biochem 60:405-412.

Pentreath VW, Kai-Kai MA (1982) Significance of the potassium signal from neurones to glial cells. Nature 295:59-61.

Peters A, Palay SL (1976) Fine structure of the nervous system: the neurons and supporting cells. Philadelphia: Saunders.

Poitry-Yamate CL, Poitry S, Tsacopoulos M (1995) Lactate released by Mfller glial cells is metabolized by photoreceptors from mammalian retina. J Neurosci 15:5179-5191.

Poole RC, Halestrap AP (1993) Transport of lactate and other monocarboxylates across mammalian plasma membranes. Am J Physiol 264:C761-C782.

Prasannan KG, Subrahmanyam K (1966) Effect of insulin on the synthesis of glycogen in cerebral cortical slices of alloxan diabetic rats. Endocrinology 82:1-6.

Quach TT, Rose C, Schwartz JC (1978) $\left[{ }^{3} \mathrm{H}\right]$ glycogen hydrolysis in brain slices: responses to neurotransmitters and modulation of noradrenaline receptors. J Neurochem 30:1335-1341.

Ransom BR, Fern R (1996) Anoxic-ischemic glial cell injury: mechanisms and consequences. In: Tissue oxygen deprivation (Haddad G, Lister G, eds), pp 617-652. New York: Dekker.

Ransom BR, Fern R (1997) Does astrocytic glycogen benefit axon function and survival in CNS white matter during glucose deprivation? Glia $21: 134-141$.

Schurr A, West CA, Rigor BM (1988) Lactate-supported synaptic function in the rat hippocampal slice preparation. Science 240:1326-1328.

Siesjö BK (1978) Brain energy metabolism. New York: Wiley.

Silver IA, Erecinska M (1994) Extracellular glucose concentration in mammalian brain: continuous monitoring of changes during increased neuronal activity and upon limitation in oxygen supply in normo-, hypo-, and hyperglycemic animals. J Neurosci 14:5068-5076.

Sokoloff L, Reivich M, Kennedy C, Des Rosiers MH, Patlak CS, Pettigrew KD, Sakurada O, Shinohara M (1977) The $\left[{ }^{14} \mathrm{C}\right]$ deoxyglucose method for the measurement of local cerebral glucose utilization: theory, procedure, and normal values in the conscious and anesthetized albino rat. J Neurochem 28:897-916.

Stryer L (1995) Biochemistry. New York: Freeman.

Stys PK, Ransom BR, Waxman SG, Davis PK (1990) Role of extracellular calcium in anoxic injury of mammalian central white matter. Proc Natl Acad Sci USA 87:4212-4216.

Stys PK, Ransom BR, Waxman SG (1991) Compound action potential of nerve recorded by suction electrode: a theoretical and experimental analysis. Brain Res 546:18-32.

Swanson RA, Choi DW (1993) Glial glycogen stores affect neuronal survival during glucose deprivation in vitro. J Cereb Blood Flow Metab 13:162-169. Swanson RA, Sagar SM, Sharp FR (1989a) Regional brain glycogen stores and metabolism during complete global ischaemia. Neurol Res 11:24-28.

Swanson RA, Yu AC, Sharp FR, Chan PH (1989b) Regulation of glycogen content in primary astrocyte culture: effects of glucose analogues, phenobarbital, and methionine sulfoximine. J Neurochem 52:1359-1365. Swanson RA, Morton MM, Sagar SM, Sharp FR (1992) Sensory stimulation induces local cerebral glycogenolysis: demonstration by autoradiography. Neuroscience 51:451-461.

Volk C, Kempski B, Kempski OS (1997) Inhibition of lactate export by quercetin acidifies rat glial cells in vitro. Neurosci Lett 223:121-124.

Walz W, Mukerji S (1990) Simulation of aspects of ischemia in cell culture: changes in lactate compartmentation. Glia 3:522-528.

Wender R, Brown AM, Ransom BR (1999) Manipulating glycogen stores in adult white matter influences nerve injury during hypoglycemia. Soc Neurosci Abstr 29:737.3.

Wiesinger H, Hamprecht B, Dringen R (1997) Metabolic pathways for glucose in astrocytes. Glia 21:22-34. 